\title{
Effect of Different Materials to Concrete as Neutron Shielding Application
}

\author{
D. SARIYER ${ }^{a, *}$ AND R. KÜÇER ${ }^{b}$ \\ ${ }^{a}$ Manisa Celal Bayar University, Turgutlu Vocational High School, Turgutlu, Manisa, Turkey \\ ${ }^{b}$ Manisa Celal Bayar University, Faculty of Arts and Sciences, Department of Physics, Muradiye, Manisa, Turkey
}

\begin{abstract}
Neutron shielding is used to protect personnel and equipment from the effect of neutron radiation. The effective neutron shielding should reduce the neutron energy by elastic and inelastic scattering until they can be absorbed. The interaction of neutron with the matter depends on neutron energy and the density of the shielding material. The best known construction and shielding material is concrete. The composition of concrete has an important effect on its neutron shielding properties. Neutron shielding performance of concrete can be improved by adding different materials such as ferro-boron and iron. In this study, neutron shielding properties of concrete were investigated by adding boron carbide $\mathrm{B}_{4} \mathrm{C}$, ferro-boron $\mathrm{FeB}$, and iron $\mathrm{Fe}$ in concrete. Neutron dose rate attenuation curves were determined by using FLUKA Monte Carlo code complemented with analytical predictions. The simulation results clearly showed that shielding performance of concrete was enhanced depending on the amounts of additional material and density.
\end{abstract}

DOI: 10.12693/APhysPolA.137.477

PACS/topics: neutron shielding, shield materials, FLUKA

\section{Introduction}

In recent years, the radiation has been used in very different fields such as nuclear physics, industrial and medical applications, etc. Radiation must be reduced with the shielding material to keep its level of the working area and surrounding environment below the dose limits determined by law and the facilities. The shielding is placed between the radiation source and an object to protect personnel and equipment from the effect of radiation [1, 2]. Neutrons are highly penetrating form of ionizing radiation. Neutron shielding is accomplishment of interaction with material by elastic and inelastic scattering until they can be absorbed. The interaction of neutron with material depends on its energy and the density of the shielding material $[3,4]$.

Concrete is the best-known construction and shielding materials but its shielding properties for high-energy neutrons is very low. The composition of concrete has an important effect on its shielding capability. The neutron interaction with shielding materials depends on neutron energy and the density of the shielding material. In order to improve the shielding performance of concrete, an additional material can be mixed into concrete. The selection criteria of the additional material for neutrons should include some properties such as high neutron cross-sections and high density to be shielded. Addition of high-density material such as ferro-boron and iron to concrete can enhance the capability of neutron resistance $[2,4,5]$.

In this study, FLUKA Monte Carlo code was used to simulate the effect of addition of different materials to

*corresponding author; e-mail: demet.sariyer@cbu.edu.tr concrete as neutron shielding application and determine the equivalent dose rates in the used shielding geometry. This dose rate is given by the following attenuation formula:

$$
H\left(\theta, \frac{d}{\lambda}\right)=\frac{H(\theta)}{r^{2}} \exp \left(\frac{-d}{\lambda_{\theta}}\right)
$$

where $r$ and $\theta$ are the spherical coordinates of the current point where the dose rate is measured, and $d$ is the total distance transferred by the radiation in the shielding material. The parameters, $\lambda_{\theta}$ are the source term and the attenuation length for the large-depth exponential function which models the equilibrium status reached [6].

\section{Material and methods}

In the shielding study for the high-energy neutrons, the effect of addition of different materials to concrete for neutron shielding application were investigated using the FLUKA Monte Carlo code. High density material is added to concrete to increase the quality of radiation resistance property. To improve the neutron attenuation properties of the concrete, selected additional materials were $\mathrm{B}_{4} \mathrm{C}, \mathrm{FeB}$, and $\mathrm{Fe}$. Boron carbide $\left(\mathrm{B}_{4} \mathrm{C}\right)$ is a ceramic material generally used for thermal neutron absorption in nuclear applications $[5,7]$. Iron and alloy of iron are good for shielding of high-energy neutrons due to the high $Z$ and low capture cross-section $[8,9]$. Ferro-boron $(\mathrm{FeB})$ is a binary alloy of iron with boron $[1,4]$.

Energetic neutrons were produced from the interaction of $1000 \mathrm{MeV}$ proton beam hitting a $5 \times 5 \times 5 \mathrm{~cm}^{3}$ copper target. Copper target was parallelepiped shaped, with the axis coincident with incoming beam direction. An abnormal operation situation at a single point was considered for the shielding modeled. Shield for the simulation geometry was modeled as a tunnel. The tunnel 
The compositions and density of the materials [10].

TABLE I

\begin{tabular}{|c|c|c|c|c|c|c|}
\hline Material & $\begin{array}{l}\text { Air inside } \\
\text { the tunnel }\end{array}$ & $\begin{array}{c}\text { Standard } \\
\text { concrete }\end{array}$ & $\begin{array}{c}\text { Boron carbide } \\
\left(\mathrm{B}_{4} \mathrm{C}\right)\end{array}$ & $\begin{array}{c}\text { Ferro-boron } \\
(\mathrm{FeB})\end{array}$ & $\begin{array}{l}\text { Iron } \\
(\mathrm{Fe})\end{array}$ & $\begin{array}{c}\text { Copper } \\
(\mathrm{Cu})\end{array}$ \\
\hline Density $\left[\mathrm{g} / \mathrm{cm}^{3}\right]$ & 0.00120484 & 2.34 & 2.52 & 7.15 & 7.84 & 8.96 \\
\hline $\begin{array}{l}\text { Element } \\
\text { and fraction [\%] }\end{array}$ & $\begin{array}{l}\mathrm{C}(0.0001248), \\
\mathrm{O}(0.231781), \\
\mathrm{N}(0.755267), \\
\operatorname{Ar}(0.012827)\end{array}$ & $\begin{array}{l}\mathrm{C}(23.0), \mathrm{O}(40.0), \\
\mathrm{Si}(12.0), \mathrm{Ca}(12.0), \\
\mathrm{H}(10.0), \mathrm{Mg}(2.0)\end{array}$ & $\begin{array}{l}\mathrm{B}(0.78261), \\
\mathrm{C}(0.21739)\end{array}$ & $\begin{array}{l}\text { Fe }(83.8), \\
\text { B }(16.2)\end{array}$ & Fe (100) & $\mathrm{Cu}(100)$ \\
\hline
\end{tabular}

TABLE II

The densities versus additional materials content in concrete, the attenuation length and the shield thickness determined general public area.

\begin{tabular}{c|c|c|c|c|c|c|c|c|c}
\hline \hline \multirow{2}{*}{ Content } & \multicolumn{3}{|c|}{$\mathrm{B}_{4} \mathrm{C}$} & \multicolumn{3}{|c|}{$\mathrm{FeB}$} & \multicolumn{3}{c}{$\mathrm{Fe}$} \\
\cline { 2 - 9 } & $\rho\left[\mathrm{g} / \mathrm{cm}^{3}\right]$ & $\lambda[\mathrm{cm}]$ & $d[\mathrm{~cm}]$ & $\rho\left[\mathrm{g} / \mathrm{cm}^{3}\right]$ & $\lambda[\mathrm{cm}]$ & $d[\mathrm{~cm}]$ & $\rho\left[\mathrm{g} / \mathrm{cm}^{3}\right]$ & $\lambda[\mathrm{cm}]$ & $d[\mathrm{~cm}]$ \\
\hline $0 \%$ & 2.340 & 49.693 & 635.145 & 2.340 & 49.693 & 635.145 & 2.340 & 49.693 & 635.145 \\
$5 \%$ & 2.349 & 49.564 & 630.448 & 2.581 & 46.294 & 586.114 & 2.617 & 45.339 & 577.718 \\
$10 \%$ & 2.358 & 49.317 & 629.602 & 2.821 & 42.807 & 543.530 & 2.893 & 41.642 & 530.309 \\
$15 \%$ & 2.367 & 47.912 & 613.357 & 3.062 & 39.011 & 500.017 & 3.170 & 38.310 & 489.746 \\
$20 \%$ & 2.376 & 47.796 & 610.291 & 3.302 & 36.969 & 470.093 & 3.447 & 35.466 & 457.474
\end{tabular}
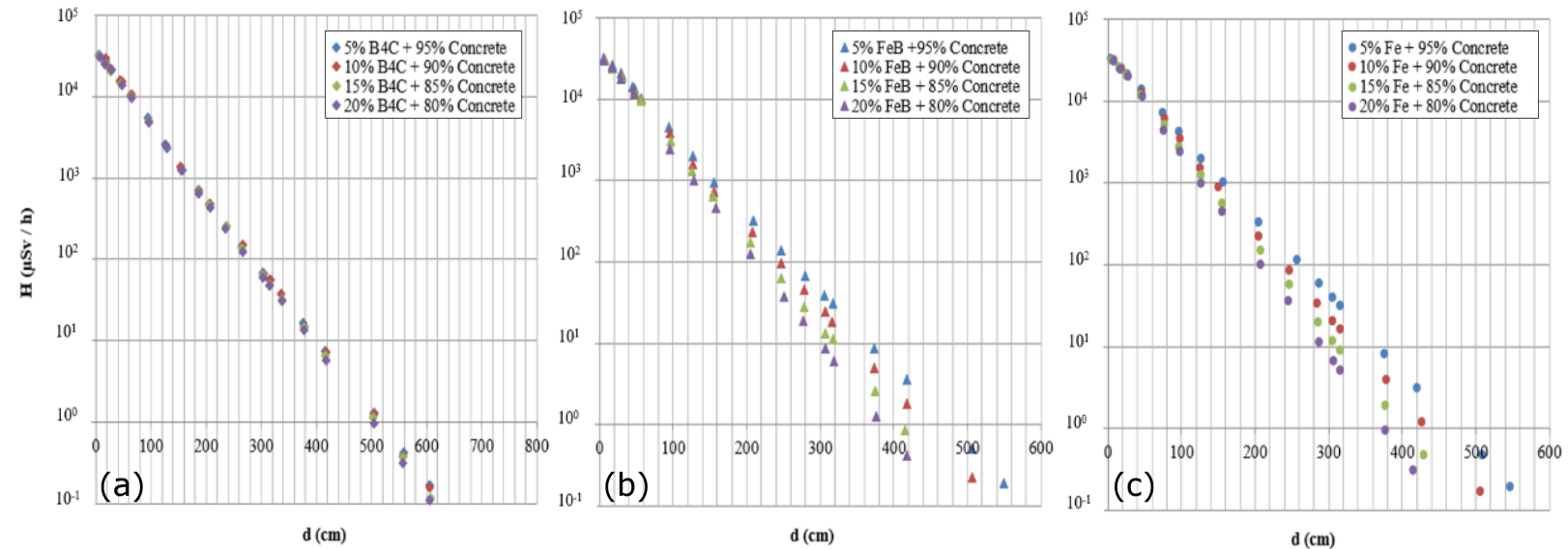

Fig. 1. Neutron dose rate attenuation curve as a function of depth in concrete containing $\mathrm{B}_{4} \mathrm{C}(\mathrm{a}), \mathrm{FeB}(\mathrm{b})$ and Fe (c).

was designed which the beam axis which placed asymmetrically side walls $2.5 \mathrm{~m}$ from away and $1 \mathrm{~m}$ from floor was $10 \mathrm{~m}$ long with inner dimensions of $5 \times 5 \mathrm{~m}^{2}$. The total shield thickness of walls made of shielding materials neutrons collided with was taken to be $24 \mathrm{~m}$. The elemental compositions and densities of the materials used for shield design are shown in Table I.

\section{Results and discussion}

An additional material type and its ratio in concrete can lead to different neutron dose distributions. Shielding properties of concrete should be improved by adding high density material in order to minimize the space required. Therefore, the neutron attenuation effects through shielding materials were investigated for some materials $\left(\mathrm{B}_{4} \mathrm{C}, \mathrm{FeB}\right.$, and $\left.\mathrm{Fe}\right)$ at different ratios of addition to concrete using FLUKA Monte Carlo code. The contents of additional materials in concrete are changed from $0 \%$ to $20 \%$. Determined neutron dose rate attenuation curves in concrete containing additional materials $\left(\mathrm{B}_{4} \mathrm{C}, \mathrm{FeB}\right.$, and $\left.\mathrm{Fe}\right)$ as a function of shield thickness are given in Fig. 1. These figures allow to determine the required thickness according to the classification of the area behind the shielding.

Table II shows the densities $\rho$ versus additional materials content in concrete, the attenuation length $\lambda$, and the required minimum shield thickness $d$ for general public area calculated by using Eq. (1) and fitted with $\theta=90^{\circ}$. Shield thickness should reduce the dose rate on the accessible levels outside surfaces of the shielding to less than $0.1 \mu \mathrm{Sv} / \mathrm{h}$. 
As seen from Fig. 1 and Table II, the shielding capability increased, and thickness decreased when materials with high densities were added into concrete. The advantage in thicknesses by adding material $(5 \%-20 \%)$ to concrete was determined as $4.697-24.854 \mathrm{~cm}$ for $\mathrm{B}_{4} \mathrm{C}$, $49.031-165.052 \mathrm{~cm}$ for $\mathrm{FeB}$, and $57.427-177.671 \mathrm{~cm}$ for $\mathrm{Fe}$. From the results, it is seen that $\mathrm{B}_{4} \mathrm{C}$ is very poorly effective against high-energy neutrons as it contains light elements. Therefore, increasing $\mathrm{B}_{4} \mathrm{C}$ content should not cause a significant change in attenuation rates. The material components of the concrete $\mathrm{B}_{4} \mathrm{C}$ are generally used for slow neutrons. It is seen that increasing the density of the concrete shield by adding $\mathrm{FeB}$ and $\mathrm{Fe}$ has a major contribution in the attenuation of neutrons because heavy weight elements are the most effective ones for the high-energy neutrons due to inelastic scattering collisions. In our previous works $[2,5]$, neutron shield effects have been seen clearly.

\section{Conclusion}

In this study, the enhancement of the neutron shielding effectiveness of concretes by adding $\mathrm{B}_{4} \mathrm{C}, \mathrm{FeB}$, and $\mathrm{Fe}$ have been investigated using the FLUKA code. The results show that composite concrete can be used as a neutron shielding material over the normal concrete particularly if its density is increased.

Neutron radiation shielding has been studied with varied materials from the past to the present day and different shielding materials have been developed and tested. In a large part of recent works composite materials are mostly preferred $[1,2,5,7,9]$. Therefore, concrete containing $\mathrm{FeB}$ and $\mathrm{Fe}$ in different ratios can be used with density and neutron resistance property.

\section{Acknowledgments}

The numerical calculations reported in this paper were performed at TUBITAK ULAKBIM, High Performance and Grid Computing Center (TRUBA Resources).

\section{References}

[1] M.S. Sarkawi, M.R.M. Zain, M.H. Rabir, F.M. Idris, J. Zainal, IOP Conf. Series Mater. Sci. Eng. 298, 012037 (2018).

[2] D. Sariyer, R. Küçer, AIP Conf. Proc. 1935, 100003 (2018).

[3] M. Nyarku, R.S. Keshavamurthy, V.D. Subramania, A. Haridas, E. Glover, Ann. Nucl. Energy 53, 135 (2013).

[4] D. Sarıer, R. Küçer, N. Küçer, Acta Phys. Pol. A 127, B-201 (2015).

[5] D. Sarıyer, R. Küçer, N. Küçer, Elsevier Proced. Soc. Behavior. Sci. 195, 1752 (2015).

[6] D. Ene, M. Brandin, M. Eshraqi, M. Lindroos, S. Peggs, H. Hahn, Progr. Nucl. Sci. Technol. 2, $382(2011)$.

[7] Y. Abdullah, M.R. Yusof, R. Mustaffa, A.A. Mohamed, F.N.T. Ariffin, N.E. Abdullah, J. Nucl. Relat. Technol. 8, 2 (2011).

[8] K. Tesch, J.M. Zazula, Nucl. Instrum. Methods Phys. Res. A 300, 179 (1991).

[9] D. Sarıyer, R. Küçer, N. Küçer, Balcan Phys. Lett. 23, 37 or 23105 (2015).

[10] P.R. Sala Ferrari, A. Fasso, J. Ranft, FLUKA: A Multi-Particle Transport Code, Rep. no. CERN2005-010, Geneva 2011. 